\title{
More pain studies needed
}

Scientists struggle to fund work on animal pain and distress.

More research is needed on how to determine when a laboratory animal is in pain and how best to alleviate that pain, says a report from the US National Research Council. That conclusion may sound familiar; a report last year called for more research into laboratory animal distress, and a 1992 study said that more work was needed on pain and distress.

However, little has been done because the root problem - lack of money for such studies - has remained for decades. "Unless or until someone comes forward with the funding, it is not going to happen," says Gerald Gebhart, a pain researcher at the University of Pittsburgh in Pennsylvania and chairman of the committee that put together the new report.

Research into animal pain tends to fall between the purviews of existing funding agencies, the biggest of which typically have human health as their goal. "All of what we know today about pain in animals - well, $95 \%$ of it - comes from research on animals as models for human

pain," says Andrew Rowan, a vice-president at the Humane Society of the United States, in Washington DC. For example, information on which pain medication regime is ideal for a mouse that has just had abdominal surgery might be gleaned from an experiment focused on what pain regime is ideal for humans.

In the United States, grants solely to study animal pain are rare and small. The funding sit-

"Pain research hasn't worked well because our animal models are inappropriate." uation is better across the Atlantic Ocean. "In Europe there is a lot of interest," says Vera Rogiers, head of the European Consensus Platform on 3R Alternatives, a non-profit organization based in Brussels. A proposal released late last year would tighten up a European Commission directive on the care of laboratory animals (see 'Europe to revise animal-testing rules'), which, among other things, would virtually ban studies on great apes, consider the pain of invertebrate species as well as vertebrates and enshrine the desirability of the three Rs: refinement, reduction and replacement.

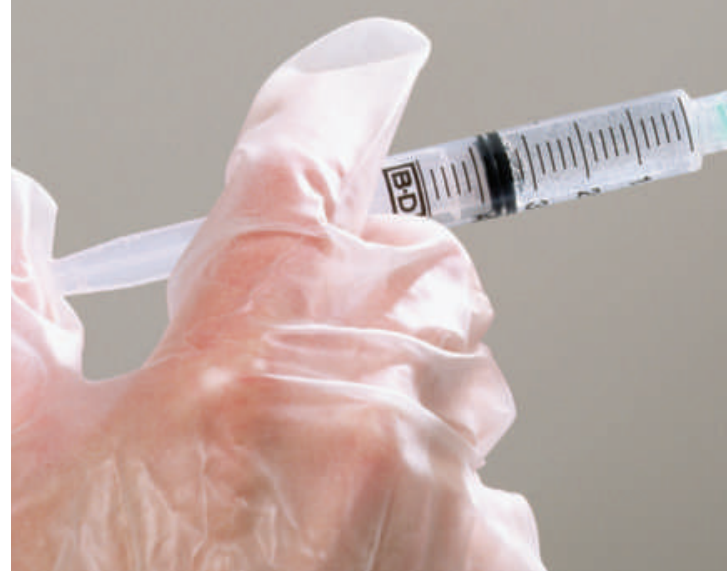

Paul Flecknell, an author of the US report at the University of Newcastle, UK, has had grants from the Wellcome Trust in London, and the UK Biotechnology and Biological Sciences Research Council, among others, to maintain his studies on behavioural clues to animal pain and distress (A. L. Dickinson, M. C. Leach and P. A. Flecknell Lab. Anim. 43, 11-16; 2009). Still, he says, money is in "very short supply" for studies in which the primary goal is to improve practices in the use of lab animals.

\section{Bills target biosimilar drugs}

Makers of biological drugs and their would-be generic competitors drew new battle lines on Capitol Hill last week, in a long-simmering debate over when and how generic versions of these large, complex drugs will enter the US market. Two California Democrats have introduced duelling bills in the House of Representatives; which one emerges as the winner - or what compromise is struck between the two - will indicate how much power and influence the industry lobby has.

In his proposed budget for 2010, President Barack Obama supports allowing the US Food and Drug Administration (FDA) to approve generic versions of biologicals, also known as biosimilars. As he seeks to cut soaring health costs, the high prices of biological drugs present an attractive target. Last year, the Congressional Budget Office estimated that a Senate bill creating a regulatory pathway for biosimilars would cut spending on prescription drugs in the United States by $\$ 25$ billion between 2009 and 2018 .

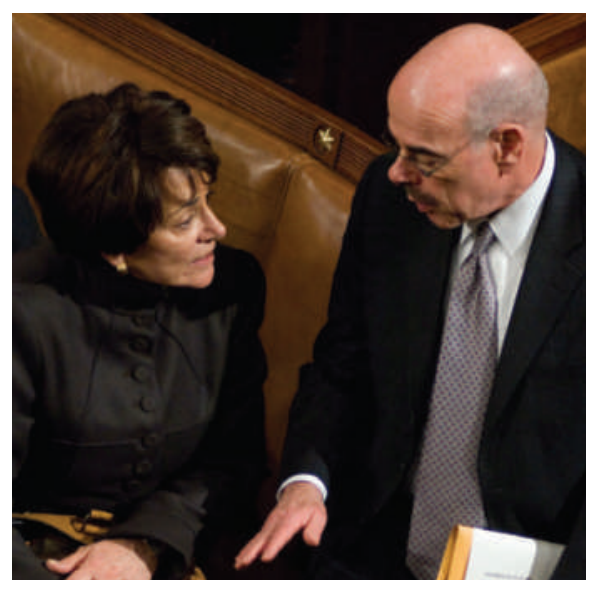

Anna Eshoo and Henry Waxman go head-to-head over drug regulation.

Other countries have set a precedent for such approval. The European Union opened up a regulatory pathway for biosimilars in 2005, and since then its European Medicines Agency has approved 13 such drugs. A number of the European guidelines have been adopted in Australia, and Japan this month issued its own guideline for the regulation of biosimilars.

In the United States, Anna Eshoo, the Democrat who represents California's biotech-heavy Silicon Valley in Congress, has introduced the Pathway for Biosimilars Act with leading co-sponsor Joe Barton (Republican, Texas). And on 11 March, Henry Waxman, the energy and commerce committee chairman from Los Angeles, introduced the Promoting Innovation and Access to Life-Saving Medicines Act, co-sponsored by Nathan Deal (Republican, Georgia) and others.

Both groups agree that a law allowing the FDA to approve biosimilars should preserve patient safety while opening up the market to healthy competition - all without squelching incentives to innovation. But they agree on almost nothing in the legislative details of how to achieve this. "The biotechnology industry has endorsed the Eshoo bill, and the generic industry has endorsed the Waxman bill. It doesn't get more extreme than that," says Mark Schoenebaum, a biotechnology analyst in 


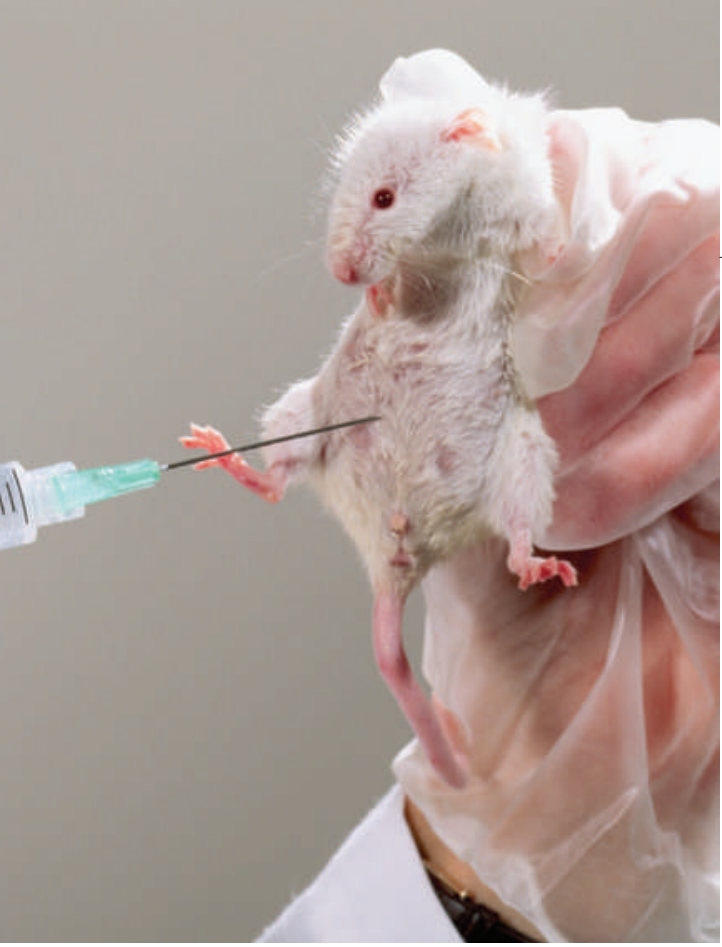

Some of his colleagues in other countries have cobbled together funding from veterinary charities and pharmaceutical companies for work on dogs and cats, and from agricultural agencies interested in poultry production for work on birds.

Animal-welfare organizations tend not to fund such research, as they focus on developing alternatives to animal research instead of refining current laboratory practices. And virtually no one funds research on pain and

\section{Europe to revise animal-testing rules}

Animal pain is one of a host of issues facing legislators, as a major revision of rules governing animal experiments makes its way through the European Parliament.

The proposals - a wholesale update of the decades-old current rules - were unveiled last year by the European Commission. The parliament's agriculture committee is scheduled to vote on them on 31 March. If the legislation can clear this committee quickly, it may be voted on by the whole parliament before the European elections in June. Under the legislation, European Union states would have to "ensure the improvement of breeding, accommodation and care, and of methods used in procedures, eliminating or reducing to the minimum any possible pain, suffering, distress or lasting harm to the animals".

Another proposed rule suggests that all experiments should be categorized on the
OIL-SPILL ANNIVERSARY Twenty years on, the lingering legacy of the Exxon Valdez.

www.nature.com/news distress in the non-mammal vertebrates, such as fish, or the invertebrate worms commonly used in neurology studies.

Supporting such research might one day have pay-offs for people. "Some of us in the pain field think that if one thinks that pain research hasn't worked particularly well there are no new drugs in the clinic, really - that our animal models are inappropriate," says Jeffrey Mogil, a pain specialist at McGill University in Montreal, Canada. basis of the pain and harm they may cause, and that lab animals should generally only be re-used in experiments classed as 'up to mild'. The exact definitions of these categories are not yet set.

Some scientists have warned that some of the rules, such as those on non-human primates, and an expected increase in bureaucracy, could make it harder to perform research on animals, as well as driving up the cost of research.

Daniel Cressey
Researchers who study human pain use animal models measuring how sensitive an animal is to touch after a painful stimulus. This 'mechanical allodynia' measures tenderness such as the pain evoked when a bruise is touched. But it does not measure 'spontaneous pain', such as the dull throb of a bruise that is not being touched. A better model of that in animals, says Mogil, could mean better treatments one day for pain in humans.

Emma Marris
New York for Deutsche Bank.

The starkest difference between the two bills - and probably the point of most heated contention in the upcoming congressional debate - is the period of market exclusivity they grant. Under Waxman, an innovator company would be guaranteed at most six years of competition-free market access. Under Eshoo, it would receive at least 12 years, and up to 14.5 years. With annual sales of leading biologicals such as Amgen's Epogen - set to come off its patents in the United States beginning in 2012 (see table) -

\section{KEY PATENTS DUE TO EXPIRE}

\begin{tabular}{|llll|}
\hline Expiry & Brand name & Generic name & Maker \\
\hline 2010 & Cerezyme & Imiglucerase & Genzyme \\
\hline 2012 & Epogen & Epoetin alpha & Amgen \\
\hline 2012 & Enbrel & Etanercept & Amgen \\
\hline 2012 & Avonex & Interferon $\beta 1 a$ & Biogen \\
2013 & Neupogen & Filgrastim & Amgen \\
\hline 2014 & Rituxan & Rituximab & Genentech \\
\hline 2015 & Neulasta & Pegfilgrastim & Amgen \\
\hline 2015 & Fabrazyme & Agalsidase beta & Genzyme \\
\hline
\end{tabular}

at more than $\$ 2.4$ billion, the stakes in what number is finally settled on are huge.

Significantly, Waxman has given ground from earlier versions of his bill, which guaranteed innovators no period of market exclusivity. Eshoo's bill, by contrast, remains essentially the same as it was in the last Congress, when a bipartisan group of leading senators also endorsed a 12-year exclusivity period. This year other senators are also expected to introduce a bill that, like Waxman's, endorses a 6-year period.

The Eshoo bill also proceeds more cautiously on other key issues, such as whether a biosimilar is interchangeable with the innovator drug, which could allow pharmacists and health plans to switch patients without a doctor's go-ahead. Before the FDA could allow this for a given biosimilar, Eshoo's bill would require the FDA to issue a 'guidance' document - an often-lengthy and public process - establishing the scientific grounds for allowing the change. Waxman's bill has no such requirement.

"Cost saving is obviously a goal here," says Sandi Dennis, the deputy general counsel for health care at the US Biotechnology
Industry Organization. "But you can't make decisions purely on cost savings without first assuring that the appropriate data are there for a new product to assure patients' safety. The science has to precede the economics."

Generics makers argue that such requirements are stalling tactics. "In these tough economic times, the Eshoo-Barton bill is a dead end for consumers," says Kathleen Jaeger, president and chief executive of the Generic Pharmaceutical Association in Arlington, Virginia. "It's just riddled with barriers. Consumers are not going to get timely access to affordable medicines."

Both bills give discretion to the FDA to work out approval requirements, such as whether clinical trials are needed to win access to the market. Brand-name makers argue that trials are crucial because biosimilars, unlike generic copies of small-molecule drugs, are not exact copies of innovator biologicals and could thus cause unexpected safety problems, such as immunological reactions. Generics makers retort that the FDA has sufficient scientific expertise to judge when trials are needed and shouldn't be required to impose them. Meredith Wadman 